\title{
La regularización en materia urbanística: lecciones del derecho francés para el caso colombiano
}

\section{Andrés Felipe MANRIQUe JAIME ${ }^{1}$}

\section{RESUMEN}

A medida que el principio de seguridad jurídica se consolida, la regularización de situaciones y actos urbanísticos se posiciona como una técnica que permite dar continuidad a la acción administrativa. Esta se convierte incluso en una intervención válida frente a los efectos tradicionales de la anulación de los actos administrativos. No obstante, su correcta aplicación impone al juez administrativo un deber de control, pues se corre el riesgo de banalizar los vicios procedimentales y de fondo que configuran el sentido original de la decisión administrativa. A partir de una comparación con el derecho francés y de un examen de los límites derivados de exigencias como el respeto por la "concepción general de la obra", se busca entender el alcance práctico que tiene la regularización urbanística en el ordenamiento jurídico colombiano.

Palabras clave: regularización, seguridad jurídica, convalidación, licencia, eficacia, anulación.

1 Abogado de la Universidad Externado de Colombia, magíster en Derecho Público de la Universidad París 2, Panthéon-Assas, París, Francia. Consultor y abogado independiente. Enlace ORCID: https://orcid.org/0000-0003-0307-3339. Correo-e: andresmanriquejaime1992@gmail.com. Fecha de recepción: 15 de octubre de 2020. Fecha de modificación: 20 de abril de 2021. Fecha de aceptación: 10 de mayo de 2021. Para citar el artículo: MANRIQUE JAIME, ANDRÉS FELIPE, "La regularización en materia urbanística: lecciones del derecho francés para el caso colombiano", Revista digital de Derecho Administrativo, Universidad Externado de Colombia, n. ${ }^{\circ} 26,2021$, pp. 263-283. DOI: https://doi.org/10.18601/21452946.n26.09. 


\title{
Urban Regularization: Lessons from French Law for the Colombian Legal System
}

\author{
ABSTRACT
}

As the principle of legal certainty consolidates, the regularization of urban planning situations and acts is positioned as a technique that allows the continuity of administrative action. It has even become a valid intervention, as opposed to the traditional effects of the annulment of administrative acts. Nevertheless, its correct application imposes a duty of review on the administrative judge, as there is a risk of trivializing the procedural and substantive flaws that shape the original meaning of the administrative decision. From a comparison with French law and an examination of the limits derived from requirements such as respect for the "overall project approach", this paper seeks to understand the practical scope of urban planning regularization in the Colombian legal system.

Keywords: Regularization, Legal Certainty, Validation, License, Efficacy, Annulment.

\section{INTRODUCCIÓN}

Según Georges Vedel, la regularización puede definirse como: "un mecanismo operacional en virtud del cual un acto o una situación jurídica contraria a derecho puede [...] perpetuarse o revivir en la legalidad plenamente recobrada" ${ }^{\prime 2}$. En este sentido, la regularización de situaciones "otorga un título jurídico a una situación de hecho" ${ }^{\prime 3}$; mientras que la regularización de actos "suprime el vicio que afecta al acto, pero a la vez retoma su parte resolutiva o dispositiva" ${ }^{\prime 4}$. Así definida, esta técnica permite a la Administración validar una situación irregular por medio de la adopción de un acto que va a darle soporte legal. De este modo, se permite que una construcción realizada sin

2 Georges Vedel, "Prefacio", en Jean-Jacques Israël, La régularisation en droit administratif français: étude sur le régime de l'acte administratif unilatéral, París: LGDJ, 1981, coll. "Bibliothèque de droit public", t. 138.

3 Louis Dutheillet de Lamothe y Guillaume Odinet, "La régularisation, nouvelle frontière de l'excès de pouvoir", AJDA, n. ${ }^{\circ} 33,2016$, p. 1859.

Ibid. 
autorización, pueda ser regularizada posteriormente a través de una licencia de construcción ${ }^{5}$.

Tratándose de su aplicación de la regularización a los actos, esta puede considerarse como "la confirmación del acto gracias a la corrección de la irregularidad que lo afectaba"6 o como el "procedimiento que busca ajustar a la legalidad un acto irregular, con el fin de salvaguardar sus efectos"7. Por ejemplo, la regularización de actos administrativos en el derecho francés forma parte de una gama de poderes con los que cuenta el juez administrativo para evitar su anulación. Su puesta en marcha pone en juego dos principios que guían la acción administrativa: el principio de legalidad y el de seguridad jurídica, siendo este último el que parece favorecerse con el recurso a la institución de la regularización.

Sin embargo, y bajo un enfoque distinto, de armonización de estos dos principios, la regularización puede abordarse como el mecanismo que permite lograr un mejor equilibrio entre la legalidad y la seguridad jurídica ${ }^{8}$, ya que al ajustar el acto a derecho, se conservan sus efectos en el ordenamiento jurídico. De acuerdo con lo anterior, la regularización parece renovar el oficio del juez administrativo, pues este deja de sancionar el actuar de la Administración con la anulación pura y simple del acto, y se dedica más bien a corregir ${ }^{9}$ y a acompañar la acción administrativa. Se tiene entonces que el principio de legalidad pasaría a considerar el efecto útil de los actos de las autoridades encargadas de su expedición.

Comparativamente, dicha mutación del principio de legalidad ha sido promovida por el juez administrativo francés, quien se muestra más consciente de todo lo que implica la elaboración del acto administrativo y de la multiplicidad de intereses que están en juego, sobre todo los económi$\cos ^{10}$. Así las cosas, el juez en Francia puede concluir que la anulación pura y simple del acto es susceptible de acarrear consecuencias desastrosas para el ordenamiento jurídico y los intereses públicos y privados involucrados en dicha decisión.

Actuando de esta forma, el juez administrativo estaría más cerca de la Administración que del demandante, pues este último es quien busca

5 CE, sect., 12 de octubre de 1956, Syndicat départemental de la boulangerie de l'Eure et Consort Simenel, n. ${ }^{\circ} 92679$ y n. ${ }^{\circ} 92680$.

6 Élise LANGELIER y Aurélie Virot-LANDAis, "Mérites et limites du recours à la régularisation des actes viciés", JCP A, n. ${ }^{\circ} 30-34,2015$, p. 2245.

7 VinCEnT Daumas, "La régularisation d'un acte illégal", RFDA, n. ${ }^{\circ} 2,2017$, p. 289, concl. sous CE, Sect., 1. ${ }^{\circ}$ de julio de 2016, Commune d'Emerainville, n. ${ }^{\circ} 363047$.

8 AudRey BACHERT, "La régularisation des actes administratifs", RDP, n. ${ }^{\circ} 1,2019$, p. 3.

9 Rozen Noguellou, "Le contentieux de l'urbanisme", AJDA, n. ${ }^{\circ}$ 4, 2020, p. 230.

10 Bernard DrobenKo, Droit de l'urbanisme, $14 .^{\text {a }}$ ed., Issy-les-Moulineaux: Gualino, 2019. 2020, p. 29. 
precisamente la protección de la legalidad mediante la desaparición retroactiva del acto, así como el restablecimiento de las cosas a su estado anterior; lo que en materia urbanística puede resultar bastante complejo, en la medida en que las licencias de construcción conducen a la materialización de obras. Como aliciente para la parte actora, y aunque la regularización purgue la ilegalidad que afecta la situación jurídica con un efecto retroactivo ${ }^{11}$, esta no exime de responsabilidad penal ${ }^{12}$.

En el derecho francés, que aquí se toma de referente para la comparación, la figura de la regularización de los actos administrativos en materia urbanística se encuentra legitimada por una política tendiente a favorecer la construcción y el acceso a vivienda digna, declarados objetivos de valor constitucional mediante decisión del Consejo Constitucional del 19 de enero de $1995^{[13]}$. Así pues, las grandes beneficiarias de esta técnica son las empresas inmobiliarias o titulares de la autorización, quienes -como litisconsortes necesarios en un contencioso triangular ${ }^{14}$ - encontrarán procedimientos de subsanación amplios y flexibles frente a eventuales irregularidades que se puedan cometer en el transcurso de expedición de la licencia de construcción. Lo anterior no pretende otra cosa que reducir la incertidumbre jurídica que pesa sobre los proyectos de construcción y, de esta manera, proteger la seguridad jurídica de los inversores.

En dicho sistema, la regularización en materia urbanística (prevista en los artículos L. 600-5, L. 600-5-1 y L. 600-9 del Código Urbano francés), puede provenir espontáneamente de la propia Administración o de la iniciativa del juez administrativo. En la última hipótesis, es decir, cuando la regularización de los actos administrativos procede por vía jurisdiccional, ella opera de dos formas. Bien sea mediante la anulación parcial del acto y la expedición posterior de un nuevo acto corrector; o mediante la promoción del juez, quien, en vez de anular el acto, suspende el proceso judicial y otorga un término a la Administración para que el acto sea subsanado. Con respecto a la anulación parcial, también se sostiene que no es más que una anulación condicionada a la regularización posterior del acto que es considerado indivisible, pero cuya ilegalidad es identificable ${ }^{15}$. En este orden de ideas, no es necesario que la anulación parcial en sentido estricto

11 Rozen Noguellou, "Régularisation et droit de l'urbanisme", RFDA, n. ${ }^{\circ}$ 2, 2018, p. 370

12 Cour de cassation, criminelle, Chambre criminelle, 16 de enero de 2018, 17-81.157.

13 Cons. const., 19 de enero de 1995, loi relative à la diversité de l'habitat, n. ${ }^{\circ}$ 94-359 DC.

14 Expresión acuñada por Daniel LABETOULLE, "Questions pour le droit administratif", AJDA, HS, 1995, p. 11.

15 En este sentido leer: RENAUD THIELE, "Annulations partielles et annulations conditionnelles", AJDA, n. ${ }^{\circ} 16,2015$, p. 1357; y HENRI BOUILLON, "La régularisation d'un acte administratif après annulation conditionnelle: une technique en gestation", AJDA, 2018, n. ${ }^{\circ} 3$, p. 142. 
esté contemplada legalmente en los textos, pues la mutilación del acto a lo estrictamente necesario para el respeto del principio de legalidad, debe ser cuestión de sentido común para el juez administrativo. Según el Consejo de Estado francés, la anulación parcial en sentido estricto procede cuando los elementos del proyecto de construcción, en razón a su autonomía arquitectural y funcional, pueden ser objeto de autorizaciones distintas ${ }^{16} ;$ se habla, por ende, de un acto administrativo divisible ${ }^{17}$. Este puede ser el caso de inmuebles independientes (CE, 16 de enero de 1970, De Fligue, n. ${ }^{\circ}$ 59145) o de una casa separada de su garaje, pero autorizados en una misma licencia de construcción (CE, 2 de febrero de 1979, Consorts Sénécal, n. ${ }^{\circ}$ 05808). A pesar de que la anulación parcial en sentido estricto no supone regularizar, esta constituye el punto de partida de la regularización en materia urbanística, pues neutraliza la anulación del acto administrativo en su totalidad y favorece el mantenimiento de sus efectos jurídicos ${ }^{18}$.

En comparación con el caso colombiano, no se observa un desarrollo similar de la regularización por parte de la Administración o de la jurisprudencia administrativa nacional, pese a que el acceso a la vivienda digna está consagrado como derecho fundamental autónomo ${ }^{19}$ en el artículo 51 de la Constitución Política y a que la Ley 3 de 1991 creó el Sistema Nacional de Vivienda de Interés Social. Es allí donde radica el interés de esta investigación, toda vez que de cara a la reactivación económica pospandemia COVID-19 y a la promulgación reciente de la Ley 2079 de $2021^{[20]}$, por medio de la cual se adoptan disposiciones en materia de vivienda y hábitat, se vislumbra un

16 CE, 17 de julio de 2009, Commune de Grenoble, n. ${ }^{\circ} 301615$ y CE, 15 de mayo de 2013, SCCV Le Clos de Bonne Brise, n. ${ }^{\circ} 341235$.

17 En lo referente a la interdependencia entre acto administrativo divisible y anulación parcial, véase HENRI BOUILLON, "Pour une subjectivisation de l'annulation partielle des actes administratifs unilatéraux", AJDA, n. ${ }^{\circ} 4,2017$, p. 217.

18 RenAud Thiele, "Annulations partielles et annulations conditionnelles", p. 1357.

19 Corte Constitucional, sentencia T-420 del 11 de octubre de 2018, expediente T-6. 739.394 .

20 Véase, en especial, su artículo 28 que modifica el artículo 36 de la Ley 388 de 1997, y que dispone lo siguiente: "Los actos administrativos de contenido particular y concreto en firme que autorizan las actuaciones urbanísticas consolidan situaciones jurídicas en cabeza de sus titulares, y obligaciones contenidas en ellas. La autoridad municipal o distrital competente, deberá respetar los derechos y obligaciones que se derivan de tales actos. Son actos administrativos de contenido particular y concreto las licencias de parcelación, urbanización, construcción y demás establecidas por la normatividad nacional". Dicho artículo parece haber modificado la naturaleza jurídica de las licencias de construcción en Colombia, toda vez que como se mencionará con posterioridad, hasta el momento, las principales cortes han sostenido que las licencias urbanísticas son simples autorizaciones de policía que no confieren derechos adquiridos. Reconociendo esta ley de seguridad jurídica a las licencias urbanísticas y en especial a las licencias de construcción, la regularización podrá empezar a desarrollarse con mayor libertad, 
aumento considerable en el recurso a la regularización en materia urbanística, así como un cambio en el precedente jurisprudencial en las cortes colombianas con respecto a la naturaleza jurídica de las licencias de construcción, tema que será abordado posteriormente. Dicho lo anterior, se revela útil la escogencia del método comparativo entre estos dos sistemas jurídicos, por cuanto, más allá de la innegable influencia tradicional que el derecho francés ha tenido en la construcción del derecho administrativo colombiano, el modelo de regularización desarrollado en Francia avizora lo que puede ocurrir en Colombia en algunos años, no solo en el ámbito de la construcción de vivienda, sino también en inmuebles de tipo dotacional, comercial o de servicios, pues ciertamente el sector de la construcción es uno de los grandes generadores de empleo. En este sentido, la presente investigación pretende evidenciar que el derecho urbano constituye uno de los principales factores de evolución del derecho administrativo, sugiriendo, por ejemplo, una nueva forma de concebir el principio de legalidad ${ }^{21}$, por intermedio de la regularización de situaciones y actos administrativos, que busca consolidar la acción administrativa.

En esta progresiva tendencia por tener en cuenta el efecto útil de los actos administrativos y salvaguardar sus efectos jurídicos, es evidente que la regularización constituye una herramienta al servicio de la Administración (1), que no obstante su practicidad, debe ser delimitada si no se quiere llegar al sacrificio excesivo del principio de legalidad (2).

\section{LA REGULARIZACIÓN EN MATERIA URBANÍSTICA COMO HERRAMIENTA AL SERVICIO DE LA ADMINISTRACIÓN}

En el ordenamiento jurídico francés, donde la seguridad jurídica parecería estar ganándole el pulso al principio de legalidad, tanto el legislador como el juez administrativo han propiciado condiciones favorables para el desarrollo de la regularización (1.1). Aunque el caso francés puede contrastar con la situación en Colombia, en donde hasta el momento el principio de legalidad impera, en la práctica la regularización en materia urbanística viene abriéndose el paso (1.2).

pues, como bien se dijo, esta institución jurídica busca preservar los efectos jurídicos de los actos administrativos.

21 Sobre este principio cardinal del ordenamiento jurídico, véase LAURENT TESOKA "Principe de légalité et principe de sécurité juridique en droit administratif français", AJDA, n. ${ }^{\circ} 40,2006$, p. 2214; y FRÉDÉRIC DIEU, "La modulation des effets des annulations contentieuses ou comment concilier principe de légalité et principe de sécurité juridique", AJDA, n. ${ }^{\circ} 44,2006$, p. 2428. 


\subsection{UNA VOLUNTAD CRECIENTE POR REGULARIZAR LOS ACTOS URBANÍSTICOS EN EL DERECHO FRANCÉS}

Antes de la reforma de la Ley ELAN (portantévolution du logement, de l'aménagement et du numérique) de 2018, la regularización en derecho urbano solo podía tomar la forma de una licencia modificatoria, que como su nombre lo indica, se limitaba a hacer modificaciones a la licencia de construcción original ${ }^{22}$. Siguiendo este enfoque, la jurisprudencia del Consejo de Estado sostuvo de forma reiterada que la regularización no podía desnaturalizar la "concepción general" o "la economía general" de la construcción ${ }^{23}$. De esta forma, si se atentaba contra la "economía general" del proyecto de construcción el único camino viable era la anulación total del acto y, en consecuencia, el depósito de una nueva solicitud de licencia de construcción ${ }^{24}$.

Ahora bien, el Consejo de Estado empleó este concepto con relativa flexibilidad ${ }^{25}$ en la medida en que consideró que "la implantación, las dimensiones o la apariencia de la construcción" ${ }^{\prime 26}$ no tenían el alcance suficiente para atentar contra la "concepción general del proyecto", y por lo tanto podían ser objeto de una licencia modificatoria ${ }^{27}$. Teniendo en cuenta el respeto por la "economía general" de la obra, la regularización de vicios de forma y de procedimiento no suscitaba mayor debate, pues se consideró que estos solo afectaban la manera en que la Administración había expedido el acto ${ }^{28}$. En razón de que estas irregularidades no eran susceptibles de modificar el contenido de fondo de la decisión administrativa, la mayoría de estos vicios eran subsanables. Así lo determinó por ejemplo el Consejo de Estado francés en el fallo SCI La Fontaine de Villiers de $2004^{[29]}$, al permitir la posibilidad de subsanar un vicio de procedimiento por medio de una licencia modificatoria. De igual modo, la omisión de ciertas formalidades, como la expedición

22 Antes de la Ley ELAN de 2018, los artículos L. 600-5 y L. 600-5-1 del Código Urbano francés se encontraban regidos por el artículo 2 de la Ordenanza n. ${ }^{\circ}$ 2013-638 del 18 de julio de 2013, relativa al contencioso del derecho urbano.

23 CE, Sect., 26 de julio de 1982, Le Roy, n. ${ }^{\circ} 23604$; CE, 4 de octubre de 2013, Mme Andrieu, Perrée, n. ${ }^{\circ} 358401$; CE, 30 de diciembre de 2015, SCI Riviera Beauvert, n. ${ }^{\circ} 375276$.

24 Materne Staub, "L'annulation partielle du permis de construire", Dr. adm., n. o. 2, 2014, comm. 16.

25 Lucie Sourzat y Clemmy Friedrich, "La régularisation en droit public", JDA, n. ${ }^{\circ} 6$, 2019, artículo 241. Recuperada de http://www.journal-du-droit-administratif.fr/?p=2369

26 En términos arquitectónicos, este concepto hace referencia a la manera como una edificación se inserta en planta desde arriba, sobre un predio.

27 CE, 30 de diciembre de 2015, SCI Riviera Beauvert, n. ${ }^{\circ} 375276$.

28 Se hace referencia particularmente a la emisión de conceptos o consultas previas a la expedición de las licencias de construcción.

29 CE, 2 de febrero de 2004, SCI La Fontaine de Villiers, n. ${ }^{\circ} 238315$ 
de conceptos, encuestas o sondeos, puede subsanarse siempre y cuando se aporten con posterioridad y no afecten el contenido de la decisión de la Administración. Paradójicamente, la regularización de vicios de fondo, los cuales sí pueden afectar el contenido de la decisión, fue reconocida con anterioridad en el fallo SARL Séri de $1994^{[30]}$. En este caso, el Consejo de Estado validó que mediante una licencia modificatoria se pudiera regularizar a posteriori el desconocimiento de una regla de fondo contenida en un plan local urbano ${ }^{31}$ (institución asimilable a un plan de ordenamiento territorial en Colombia). Lo anterior evidencia que la regularización en derecho urbano francés ha tenido las puertas abiertas desde hace mucho tiempo, incluso con anterioridad al fallo Société KPMG de $2006^{[32]}$, que consagró la seguridad jurídica como principio general del derecho. En este camino por favorecer el posicionamiento de la regularización, el Consejo de Estado ha permitido que incluso la falta de competencia pueda ser subsanada ${ }^{33}$, a pesar de que este vicio esté asociado a la integralidad del acto ${ }^{34}$.

En cuanto a la segunda forma de regularización jurisdiccional, es decir, la suscitada por el juez administrativo, que suspende el proceso judicial mientras otorga un término a la Administración para que el acto sea subsanado, encontramos que esta fue producto de las proposiciones del informe de trabajo "Construction et droit au recours: pour un meilleur équilibre" (Construcción y derecho al recurso: por un mejor equilibrio) del 25 de abril de 2013, presidido por la presidencia honoraria del Consejo de Estado francés. Dicho informe estuvo inspirado en la voluntad de consolidar aún más la seguridad jurídica en el derecho urbano ${ }^{35}$.

Este modo de regularización contemplado en el artículo L.600-5-1 del Código Urbano fue reforzado a su vez por la Ley ELAN de 2018, que permitió la posibilidad de regularizar aun cuando las obras hayan terminado y convirtió la regularización en la regla y la anulación del acto en la excepción. Por consiguiente, frente a un recurso que busque la nulidad de una licencia de construcción, el juez debe, ante todo, propiciar la regularización-siempre y cuando esta sea posible- y al no hacerlo, debe fundamentar las razones por las cuales prefirió optar por la anulación del acto administrativo ${ }^{36}$.

31 VincEnt Daumas, "La régularisation d'un acte illégal", RFDA, n. ${ }^{\circ}$ 2, 2017, p. 289, concl. sous CE, Sect., 1. ${ }^{\circ}$ de julio de 2016, Commune d'Emerainville, n. 363047. CE, Ass., 24 de marzo de 2006, Société KPMG, n. ${ }^{\circ} 288460$. Lucie Sourzat y Clemmy Friedrich, "La régularisation en droit public", JDA, n. ${ }^{\circ} 6$, 2019, p. 241. p. 765 . 
Ahora bien, incluso en países como Colombia, donde la regla general sigue siendo este último proceder, es decir, la anulación retroactiva del acto administrativo, se empieza a concebir de otra forma el principio de legalidad, todo como consecuencia de la consolidación del principio de seguridad jurídica, que ha permeado la mayoría de ordenamientos jurídicos en el mundo.

\section{2. ¿PREVALENCIA DEL PRINCIPIO DE LEGALIDAD \\ EN EL CASO COLOMBIANO?}

Contrariamente a lo que sucede en Francia, y pese a que la seguridad jurídica es un principio del ordenamiento jurídico colombiano, este no es predicable de las licencias urbanísticas. Así lo ha sostenido el Consejo de Estado colombiano en múltiples providencias ${ }^{37}$. Su posición es clara y uniforme al afirmar lo siguiente en sentencia del 28 de agosto de $2014^{[38]}$ :

En esa medida, una licencia urbanística puede ser revocada o anulada total o parcialmente por ser contraria a las normas del respectivo POT o, en su caso, a las disposiciones de la UPZ (Unidad de Planeación Zonal) que desarrollan el planeamiento general. $O$ puede también suceder que una licencia se otorgue para una obra específica y ello sea legítimo, pero que con posterioridad el uso que se le da al inmueble no sea compatible con las normas urbanísticas que se expidan con posterioridad; evento en el cual se tendrá que ajustar la actividad o realizarla en otro sector. Y también podría suceder que un inmueble legítimamente construido y aprovechado por un tiempo, por virtud de los cambios en la dinámica de los usos de suelo y de los ajustes a las normas urbanísticas que los regulan, termine contraviniendo dicha reglamentación de usos, supuesto en el cual tendrá que ajustarse a ellos o desplazarse a un sector en el cual dicha actividad sea admisible. En síntesis, las licencias son actos que se encuentran subordinados al interés público en general y al cumplimiento del POT y de las específicas condiciones indicadas en ellas en particular. Por lo tanto, conforme se ha explicado de manera precedente, los derechos o situaciones jurídicas particulares nacidas con ocasión de una licencia urbanística no son absolutas ni inmodificables en el tiempo.

De acuerdo con esta postura, las licencias urbanísticas son simples "autorizaciones de policía"39 que no conceden derechos adquiridos, pues las normas sobre el uso del suelo son cambiantes y de orden público.

37 Sentencias del Consejo de Estado, Sección Primera, 12 de agosto de 1999, expediente 5.500; 11 de mayo de 2000, expediente 2000-4620; y 29 de abril de 2015, rad. 25000 23-24-000-2011-00329-01 (AP).

38 Consejo de Estado, Sección Primera, sentencia de 28 de agosto de 2014, expediente 76001-23-31-000-2004-02807-01.

39 Jorge EnRIQUE SANTOS RodríGUEZ, "La impugnación administrativa de las licencias urbanísticas", Revista digital de Derecho Administrativo, n. ${ }^{\circ} 2$, 2009, pp. 83-103. 
En línea con esta posición, la Corte Constitucional ha considerado que las licencias de construcción son actos administrativos provisorios, subordinados al interés público y, por lo tanto, a los cambios que van aparejados a este. Así pues, la expedición de licencias de construcción obedece a un poder de policía conferido a la Administración local, del cual no se puede predicar seguridad jurídica ${ }^{40}$. En este sentido, es posible sostener que la regularización en derecho urbano colombiano no tiene cabida y, en consecuencia, la balanza entre los principios de seguridad jurídica y legalidad tendería a inclinarse nítidamente en favor de este último; contrariamente a lo que sucede en Francia.

No obstante, este razonamiento no es del todo cierto o por lo menos merece ser matizado. Contrario a lo sostenido por el Consejo de Estado colombiano en esta jurisprudencia, creemos que en materia urbanística la regularización jurisdiccional parece comenzar a tomar cierta relevancia, y aún si siguen profiriéndose decisiones que limitan el oficio del juez administrativo ${ }^{41}$. En primera medida, encontramos que el artículo 3 del Código de Procedimiento Administrativo y de lo Contencioso Administrativo (CPACA) dispone en su numeral 11 que las autoridades, en virtud del principio de eficacia, buscarán que los procedimientos logren su finalidad, para lo cual removerán de oficio los obstáculos puramente formales y sanearán, de acuerdo con lo que disponga el código los vicios procedimentales que puedan afectar las actuaciones administrativas. Se considera, por tanto, que este principio permite a la Administración corregir, subsanar o regularizar sus actos, aun cuando ya hayan sido emitidos. En este sentido, si la autoridad competente se da cuenta de que existen ciertas irregularidades en la licencia de construcción que acaba de emitir, espontáneamente podrá subsanarlas previo consentimiento del titular de la autorización. Todo en aras de preservar el efecto útil de los actos administrativos y de evitar la declaración de nulidad de la licencia por parte del juez administrativo. No olvidemos que en la práctica la Administración o las curadurías urbanas suelen regularizar las licencias de construcción a través de licencias modificatorias que permiten cubrir obras no autorizadas en la licencia original o autorizaciones que se encuentran vencidas. A su vez, el término "regularización" es empleado por el artículo 2.2.6.5.1 (entre otros) del Decreto 1077 de $2015^{[42]}$ para hacer referencia al reconocimiento y la legalización de edificaciones o asentamientos humanos

40 Corte Constitucional, Sala Plena, sentencia C-192, 20 de abril de 2016, expediente D-10974.

41 Consejo de Estado, Sección Primera, sentencia de 14 de agosto de 2014, radicación 13001-23-31-000-1993-09425-01; Consejo de Estado, Sección Cuarta, sentencia de 20 de noviembre de 2019, radicación 11001-03-15-000-2019-04536-00 (AC).

42 Modificado por el Decreto 149 de 2020. 
informales, siempre y cuando se adapten a la normativa vigente. Así pues, mediante acto administrativo se le otorga un título jurídico a una situación material que en un principio fue irregular.

De conformidad con este artículo, "la legalización urbanística es el proceso mediante el cual la Administración [...] reconoce, si a ello hubiera lugar, la existencia de un asentamiento humano con condiciones de precariedad y de origen informal, conformado por viviendas de interés social y usos complementarios que la soportan, que se ha construido sin licencia de urbanización previo a su desarrollo o que aun cuando lo obtuvo, esta no se ejecutó"; ${ }^{\prime}$ mientras que según el artículo 2.2.6.4.1.1 del mencionado Decreto $^{43}$ el reconocimiento de edificaciones es la actuación ejercida por el interesado ante la autoridad competente para expedir licencias urbanísticas, tendiente a declarar mediante acto administrativo la existencia de desarrollos arquitectónicos que se ejecutaron sin haber obtenido la respectiva licencia.

En el campo jurisdiccional, a continuación, se analiza cómo ha procedido el Consejo de Estado colombiano frente a solicitudes de nulidad de licencias de construcción y si ha optado o no por el camino de la regularización. Mediante sentencia del 13 de noviembre de $2008^{[44]}$, la Sección Primera del Alto Tribunal declaró la nulidad de una licencia de construcción por un vicio de procedimiento, ya que, al demandante en su calidad de vecino, se le había vulnerado su derecho de defensa al no comunicársele en debida forma y tiempo la existencia de una solicitud de licencia, tal y como lo disponía el artículo 65 de la Ley 9 de 1989. Como medida de restablecimiento del derecho, esta corporación ordenó reiniciar toda la actuación administrativa, con sujeción al debido proceso, sin que fuere necesario tramitar una nueva licencia. Asimismo, habida cuenta que la licencia autorizaba la construcción de 449 viviendas unifamiliares, la Sala se vio en la obligación de precisar que la nulidad no afectaba las edificaciones ya construidas, las cuales se amparaban en el principio de la confianza legítima. El actor en este proceso era una estación de servicio, que se veía obligada a trasladar sus actividades en virtud de un cambio repentino en el ordenamiento territorial del municipio. La Sala aprovechó esta sentencia para recordar que no toda irregularidad en un trámite Administrativo conlleva la nulidad del mismo, sino solo en la medida en que el vicio vulnere el derecho de defensa ${ }^{45}$. A contrario sensu, si el vicio procedimental o de forma no afecta el derecho de defensa, este se puede obviar o neutralizar, rescatando así el acto administrativo.

43 Ibid.

44 Consejo de Estado, Sección Primera, sentencia de 13 de noviembre de 2008, radicación 76001-23-25-000-1997-24274-01.

45 Consejo de Estado, Sección Primera, sentencia de 18 de julio de 2001, radicación 25000-23-24-000-1992-2935-01 (6215). 
Como primera observación a este fallo, podemos anotar que, pese a que la licencia estaba viciada por un vicio procedimental de carácter sustancial, no se ordenó la demolición de las edificaciones como consecuencia de la nulidad del acto. Conforme a lo anterior, el Consejo de Estado dio paso a la regularización de una situación jurídica, al ordenar que al actor se le tenía que dar la oportunidad de pronunciarse con respecto a la licencia de construcción. Sin embargo, desde la perspectiva de la regularización de la licencia de construcción, creemos que no era necesario declarar la nulidad del acto, pues bastaba con que en la etapa de defensa se le hubiera concedido al demandante un término razonable para el traslado de su actividad, previa recepción de sus argumentos. Tal vez de esta forma, la Sala hubiera evitado recurrir al principio de la confianza legítima para proteger las edificaciones existentes.

Con este proceder, el Consejo de Estado tuvo en cuenta no solo todo lo que implicó la elaboración de la licencia, sino también las situaciones consolidadas de los propietarios de las viviendas. En consecuencia, optó por no ordenar la demolición de las edificaciones y por no exigir una nueva solicitud de licencia, lo que a todas luces hubiese sido demasiado engorroso e innecesario.

Frente a eventos como el anteriormente expuesto, sería interesante que se previera una etapa procesal en la que el juez administrativo propiciara la regularización del acto -siempre y cuando fuere esta posible-, otorgando a la Administración un término razonable para llevarla a cabo, tal y como sucede en el derecho francés.

Sin embargo, esta no es la única forma en que puede operar la regularización. El fallo analizado también puede ser visto como la regularización de una situación jurídica huérfana de sustento legal, como consecuencia de la anulación de la licencia de construcción. Ahora bien, pese a que de esta decisión se pueda corroborar una regularización post anulación del acto administrativo, la providencia que a continuación se expondrá da un paso atrás, al anclar el oficio del juez administrativo a una anulación platónica del acto administrativo. En efecto, mediante sentencia del 8 de julio de 2010 ${ }^{[46]}$, la Sección Primera del Consejo de Estado declaró la nulidad "a secas" de una licencia de construcción que desconoció la obligación de comunicarse a los vecinos y que violaba el Plan de Ordenamiento Territorial (POT) del respectivo municipio, pues la edificación de diez plantas superaba las cuatro permitidas en ese sector.

Contrariamente a lo decidido en la sentencia anterior ${ }^{47}$, el alto Tribunal se limitó a anular pura y simplemente la licencia de construcción. Del mismo

46 Consejo de Estado, Sección Primera, sentencia de 8 de julio de 2010, radicación 76001 23-31-000-1999-20550-01.

47 Sentencia de 13 de noviembre de 2008. 
modo, la Sala se negó a ordenar la demolición de la edificación, pese a que había sido solicitada por el demandante y a que la licencia se encontraba viciada tanto por vicios procedimentales como de fondo. Esta decisión puede ser objeto de discusión, habida cuenta que desconoce el principio de legalidad, al avalar una construcción carente de sustento jurídico sin ni siquiera haber procurado la corrección o subsanación del acto en cuestión. Asimismo, este fallo resta eficacia al medio de control de nulidad y restablecimiento del derecho frente a las pretensiones del demandante, puesto que este solamente se vio compensado económicamente. Dicho esto, las razones de esta decisión puede que se encuentren en la confianza legítima de los propietarios y en la dificultad material de restablecer las cosas a su estado anterior.

Luego, encontramos la sentencia de 14 de agosto de 2014 del Consejo de Estado en la que esta corporación parece confirmar la postura ${ }^{48}$, en la que el juez se limita a declarar la nulidad pura y simple de la licencia de construcción en cuestión. Sin embargo, pocos días después, el Consejo de Estado vuelve a abrir la puerta a la regularización mediante sentencia de 28 de agosto de $2014^{[49]}$. En este fallo, el alto tribunal anuló parcialmente una licencia de construcción contraria a las disposiciones del POT del municipio de Cali, que fijaba la altura máxima de las construcciones. La Sala juzgó legal la construcción limitada a tres pisos y no a cuatro, tal y como había sido autorizada en la licencia de construcción original. De esta forma, el Consejo de Estado condicionó la legalidad del acto al respeto por la altura máxima permitida en el respectivo POT. Para esto, ordenó al alcalde de la ciudad de Cali adoptar las medidas tendientes a restablecer el patrimonio urbano de acuerdo con el POT:

SEGUNDO.- Declárase la nulidad parcial de la Resolución n. ${ }^{\circ}$ CU1-0493 de agosto 22 de 2002, por medio de la cual se expide una licencia de construcción para desarrollar un proyecto de construcción nueva expedida por la Curaduría n. ${ }^{\circ} 1 \mathrm{de}$ Santiago de Cali, en el entendido de que la nulidad se limitará a la autorización para la construcción de cuatro (4) pisos, pues lo permitido son sólo tres (3) pisos.

TERCERO.- Ordenase al Alcalde Municipal de Santiago de Cali, adelantar las actuaciones administrativas a que haya lugar para restablecer el patrimonio urbanístico de la ciudad previsto en el Plan de Ordenamiento Territorial, acorde con lo dispuesto en la Ley 388 de 1997.

48 Consejo de Estado, Sección Primera, sentencia de 14 de agosto de 2014, radicación 13001-23-31-000-1993-09425-01.

49 Consejo de Estado, Sección Primera, sentencia de 28 de agosto de 2014, radicación 76001-23-31-000-2004-02807-01. 
Se trata de un fallo significativo, ya que con él se abre el camino a la regularización de un acto por un vicio de fondo, como es el desconocimiento de las disposiciones de un POT. Tal como se mencionó con la posibilidad de regularizar vicios de forma o de procedimiento, haría falta que, dentro del mismo proceso de nulidad, se dispusiera de una etapa procesal en la que el juez administrativo verificara que la regularización operó correctamente.

Decisiones como esta se podrán reproducir con mayor frecuencia, teniendo en cuenta que el artículo 28 de la Ley 2071 de 2021 reconoce ahora derechos adquiridos en las licencias urbanística ${ }^{50}$, presupuesto esencial para que la regularización se desarrolle con mayor libertad en el ordenamiento jurídico.

Si bien se observa con buenos ojos la posibilidad de regularizar los vicios que no alteren la esencia o el sentido de la decisión final, es necesario que la regularización tenga límites claros, habida cuenta que su utilización desmedida puede conllevar su degradación y a la banalización del principio de legalidad.

\section{LA DELIMITACIÓN NECESARIA A LA APLICACIÓN DE LA REGULARIZACIÓN EN MATERIA URBANÍSTICA}

Como bien se mencionó, la regularización es un mecanismo que busca mantener los efectos del acto inicial, reparando las irregularidades que lo afectan, por medio de la expedición de un acto rectificativo. No obstante, su desarrollo progresivo puede conllevar que sus límites sean cada vez más difusos y que en esta medida sea necesario advertir sobre sus posibles consecuencias en el ordenamiento jurídico (2.1). Afortunadamente, la regularización cuenta con mínimos innegociables que podrían evitar su envilecimiento por indebida y desbordada aplicación (2.2).

\subsection{VoCES DE ALERTA SOBRE El ALCANCE DE LA REGULARIZACIÓN}

Pese a que el Consejo de Estado francés ha limitado la regularización al respeto por la "concepción general de la obra" (término que desde entonces se manejaba con relativa flexibilidad), la Ley ELAN de 2018 levantó esta barrera. En adelante, la regularización no se limitará a una simple "licencia modificatoria" sino a "medidas de regularización", lo que conlleva la posibilidad de subsanar irregularidades más allá del simple respeto por el proyecto de construcción original ${ }^{51}$.

50 De acuerdo con lo anterior, la regularización será igualmente predicable de las licencias de urbanización, parcelación y subdivisión.

51 Rozen Noguellou, "Régularisation et droit de l'urbanisme", p. 370. 
Con el objetivo de evitar que el uso indebido y desbordado de la regularización socave por completo el principio de legalidad, se observa con preocupación como esta reforma levantó la barrera que consistía en el respeto de la "concepción general de la obra". En nuestro sentir, dicho límite le daba sustento jurídico a la regularización de los actos expedidos en materia urbanística, pues como bien se mencionó en la introducción, regularizar no es más que corregir o suprimir las ilegalidades del acto, sin modificar el sentido o alcance de la decisión.

Dada la incertidumbre que esto produce en los operadores jurídicos, recientemente el juez administrativo francés se vio obligado a dilucidar dicha cuestión. En efecto, mediante decisión consultiva de 2 de octubre de $2020^{[52]}$, el alto tribunal conceptuó que efectivamente la afrenta a la "economía general del proyecto" dejó de ser "decisiva"53, pero al mismo tiempo recalcó que un vicio que la transforme o la altere por completo, de tal forma que modifique su naturaleza, no podrá ser regularizado. Al analizar esta decisión otra parte de la doctrina va más allá para concluir que incluso la alteración sustancial de la "economía general del proyecto" no es más un obstáculo para la regularización de las licencias de construcción ${ }^{54}$. Esta diversidad de alcances que supone la decisión del Consejo de Estado francés podría generar aún más confusión en los jueces administrativos, ya que no existe un criterio claro y objetivo que permita determinar cuándo un vicio tiene el alcance de modificar completamente la naturaleza del proyecto de construcción. En consecuencia, además de propiciar el proferimiento de sentencias diametralmente opuestas en tribunales y cortes administrativas de apelación, la decisión analizada podría permitir que la regularización opere en cualquier clase de vicio, incluso los considerados insubsanables, como la falta de competencia absoluta o la desviación de poder ${ }_{i}$ cuestiones estas que deberá resolver el Consejo de Estado como tribunal de cierre y de unificación de jurisprudencia.

Pese a lo anterior y a que los vicios subsanables sean tratados con relativa flexibilidad en la jurisprudencia francesa ${ }^{55}$, existen barreras que consideramos infranqueables en cuanto al ejercicio de la regularización en materia urbanística.

52 CE, sect., 2 de octubre de 2020, n. ${ }^{\circ} 438318$

53 MARC PASTOR, "Portée de la procédure de régularisation des autorisations d'urbanisme", Dalloz actualité, n. ${ }^{\circ}$ 7. 2020.

54 JULIEN MARTIN, "Régularisation des autorisations d'urbanisme: cun bouleversement sans conséquence?", Dr. Adm., n. ${ }^{\circ}$ 12, 2020, comm. 52.

55 HENRI BOUILLON, "La régularisation d'un acte administratif après annulation conditionnelle", p. 142. 


\subsection{LÍMITES INNEGOCIABLES A LA POSIBILIDAD DE REGULARIZAR SITUACIONES Y ACTOS URBANÍSTICOS}

Se hace referencia pues a ilegalidades que por el simple paso del tiempo o por su naturaleza ${ }^{56}$ no tienen por qué ser subsanadas. Con respecto al primer grupo de irregularidades insubsanables, sabemos que el artículo L.600-5-1 del código urbano le otorga al juez administrativo la facultad de fijar un término razonable para que la Administración pueda regularizar el acto. Si la administración no subsana las irregularidades en este término, se podría concluir que caduca la posibilidad de corregir el acto y, en consecuencia, hay lugar a declarar la nulidad de la licencia de construcción ${ }^{57}$. Se estima que es esta la postura correcta, pues frente al acelerado desarrollo de la regularización en derecho urbano francés, este proceder del juez procura ponerle un freno a su utilización, disciplinando la acción administrativa en beneficio del principio de legalidad. En lo referente al segundo grupo, es decir, a las irregularidades que por su naturaleza no pueden ser subsanadas, encontramos las construcciones edificadas en zonas no autorizadas por el plan local urbano ${ }^{58}$, así como las construcciones localizadas en zonas expuestas a riesgo de inundación ${ }^{59}$, ilegalidad que -no sobra decirlo-, atenta contra la propia vida e integridad de los residentes.

En Colombia, la situación es bastante similar, pues en sentencia de 1 de agosto de 2019 ${ }^{[60]}$, el Consejo de Estado confirmó un fallo del Tribunal Administrativo de Cundinamarca, Subsección A, que declaró la nulidad de una licencia de construcción pues desconocía las disposiciones del Plan Básico de Ordenamiento Territorial (РВOT) del municipio de La Vega, que establecían la prohibición de construir urbanizaciones en la ronda de los ríos.

Esta situación había sido advertida por la Corporación Autónoma Regional de Cundinamarca a través de un concepto técnico, en el que además de ordenar respetar "los treinta metros de la ribera del río"61, también señaló que "la construcción de las casas no resultaba viable ambientalmente, [...] por los antecedentes de desbordamiento del mencionado río"62.

56 Michael Richard, "Une arme de régularisation massive des permis? L'article L. 600 5-1 du Code de l'urbanisme", AJDA, n. ${ }^{\circ} 42,2016$, pp. 2359-2368.

57 CAA Marseille, 15 de junio de 2015, n. ${ }^{\circ} 12 \mathrm{MA01766}$, y 21 de julio de 2016, n. ${ }^{\circ}$ 14MA00803.

58 TA Lyon, 29 de septiembre de 2016, n. ${ }^{\circ} 1409337$.

59 CAA Bordeaux, 9 de febrero de 2016, n. ${ }^{\circ}$ 14BX00420.

60 Consejo de Estado, Sección Primera, sentencia de 1. ${ }^{\circ}$ de agosto de 2019, radicación 25000-23-24-000-2011-00297-01.

61 Ibid.

62 Ibid. 
Con respecto a otras irregularidades, el artículo 2.2.6.4.1.2 del Decreto 1077 de 2015 ofrece ciertas luces acerca de los vicios que no son regularizables, por cuanto dispone que no se reconocerán edificaciones que se encuentren localizadas en áreas o zonas de protección ambiental, y en zonas declaradas como de alto riesgo no mitigable en los instrumentos de ordenamiento territorial. De acuerdo con lo anterior, las licencias que autoricen construcciones en zonas susceptibles de derrumbe o en una reserva natural, no podrían ser regularizadas y, por ende, lo que procede es la anulación del acto junto con la demolición de la edificación. Siguiendo con esta política de protección al medio ambiente y prevención de desastres naturales, encontramos que, frente a la posibilidad de regularizar actos administrativos de carácter general, como por ejemplo un POT o los actos e instrumentos que lo ajustan, la posición del Consejo de Estado es también restrictiva ${ }^{63}$. Es precisamente en este evento donde se solicita al juez que a través de la figura de la "convalidación del acto administrativo" constate la subsanación o corrección de las irregularidades cometidas a lo largo del proceso de expedición del documento.

Para ilustrar esta situación, podemos citar el fallo de 22 de marzo de $2018^{[64]}$, en el que la Sección Quinta del Consejo de Estado confirmó la sentencia de la Sala Novena del Tribunal Administrativo de Antioquia, que declaró la nulidad de un acuerdo municipal que ajustaba y revisaba el Plan Básico de Ordenamiento Territorial (PBOT) del Municipio de la Ceja (Antioquia). En este caso, el acuerdo municipal se había expedido irregularmente, al no haber contado con el concepto previo favorable de la autoridad ambiental. Pese a que la Administración lo aportó posteriormente, los jueces administrativos se negaron a aceptar la convalidación del acto, pues en su sentir, dicho requisito previo constituye una formalidad sustancial insubsanable que redunda en beneficio del medio ambiente.

Sin embargo, vale la pena preguntarse: ces justificable reiniciar toda la actuación administrativa tendiente a actualizar un instrumento de ordenamiento territorial, pese a que ya se cuenta con el concepto previo favorable de la autoridad ambiental? En nuestra opinión, este proceder es demasiado drástico y poco pragmático. Empero, desde otro punto de vista, esta decisión es el fiel reflejo de que, en materia de protección al medio ambiente, el juez administrativo es inflexible y privilegia sin ninguna duda el principio de legalidad, que busca entre otras cosas disciplinar el actuar de la Administración.

63 Consejo de Estado, Sección Quinta, sentencia de 22 de marzo de 2018, radicación 05001-23-31-000-2008-00254-01.

64 Ibid. 


\section{CONCLUSIONES}

Es posible concluir que, contrario a lo que afirma el Consejo de Estado colombiano, en sentencia de 28 de agosto de 2014, no es del todo cierto que no se pueda predicar seguridad jurídica de las licencias de construcción; el principio de confianza legítima y la institución de la regularización juegan un rol fundamental en el respeto por los derechos adquiridos de los titulares o beneficiarios de estas autorizaciones. En este camino por valorar el efecto útil de los actos administrativos y por observar el principio de eficacia en las actuaciones administrativas, tanto el Consejo de Estado colombiano como su homólogo francés han desarrollado mecanismos que buscan evitar la anulación pura y simple de los actos administrativos. Entre ellos podemos encontrar la neutralización de vicios de forma y de procedimiento que no tienen el alcance de modificar el sentido de la decisión o que no han desconocido el derecho de defensa. Así lo reconoció el mismo Consejo de Estado colombiano en sentencia de 18 de julio de 2001; mientras que el Consejo de Estado francés evidenció la materialización de dicha política jurisprudencial, en materia urbanística, mediante fallo de 17 de julio de $2013^{[65]}$, siguiendo los lineamientos de la decisión Danthony de 2011 ${ }^{[66]}$.

Aunque la puesta en marcha de la regularización suponga un correlativo debilitamiento del principio de legalidad, es preferible promover su utilización que declarar nulidades de licencias de construcción o carentes de todo efecto práctico, pues las construcciones seguirán inevitablemente en pie. Así se evidenció en la sentencia de 8 de julio de 2010 del Consejo de Estado colombiano, en el que el medio de control de nulidad y restablecimiento del derecho no resultó ser un recurso eficaz frente a las pretensiones del demandante. Por último, si la regularización no concilia de manera adecuada los principios de seguridad jurídica y de legalidad, se corre el riesgo de que el actuar de la administración carezca de todo tipo de control y rigor.

\section{BIBLIOGRAFÍA}

\section{DOCTRINA}

BACHERT, AUDREY. "La régularisation des actes administratifs". RDP, n. ${ }^{\circ}$ 1, 2019.

BOUILLON, HenRI. "La régularisation d'un acte administratif après annulation conditionnelle: une technique en gestation". AJDA, n. ${ }^{\circ}$ 3, 2018. 
Bouillon, Henri. "Pour une subjectivisation de l'annulation partielle des actes administratifs unilatéraux", AJDA, n. ${ }^{\circ}$ 4, 2017.

DAUMAS, VinCENT. "La régularisation d'un acte illégal". RFDA, n. ${ }^{2}$ 2, 2017.

DieU, FréDÉRIC. "La modulation des effets des annulations contentieuses ou comment concilier principe de légalité et principe de sécurité juridique". AJDA, n. ${ }^{\circ} 44,2006$.

DrobenKo, Bernard. Droit de l'urbanisme. Issy-les-Moulineaux: Gualino, 2019-2020.

Dutheillet de LAmothe, Louis, y Guillaume Odinet. "La régularisation, nouvelle frontière de l'excès de pouvoir". AJDA, n. ${ }^{\circ} 33,2016$.

ISRAËL, JEAN-JACQUES. La régularisation en droit administratif français: étude sur le régime de l'acte administratif unilatéral. París: LGDJ, 1981.

Labetoulle, Daniel. "Questions pour le droit administratif". AJDA, HS, 1995

LANGELIER, ÉliSe, y AurÉlie Virot-LANDAis. "Mérites et limites du recours à la régularisation des actes viciés". JCP A, n. ${ }^{\circ}$ 30-34, 2015.

MARTIN, JULIEN. "Régularisation des autorisations d'urbanisme: un bouleversement sans conséquence?". Dr. adm., n. ${ }^{\circ} 12,2020$.

Noguellou, Rozen. "Le contentieux de l'urbanisme". AJDA, n. ${ }^{\circ}$ 4, 2020.

Noguellou, Rozen. "Régularisation et droit de l'urbanisme". RFDA, n. ' 2, 2018.

PASTOR, MARC. "Portée de la procédure de régularisation des autorisations d'urbanisme". Dalloz actualité, n. ${ }^{\circ}$ 7, 2020.

RiCHARD, MiCHAEL. "Une arme de régularisation massive des permis? L'article L. 600-5-1 du Code de l'urbanisme". AJDA, n. ${ }^{\circ} 42,2016$.

SAntos RodríGueZ, Jorge EnRIQUe. "La impugnación administrativa de las licencias urbanísticas". Revista digital de Derecho Administrativo, n. ${ }^{\circ}$ 2, 2009.

SeILler, Bertrand. "Sécurité juridique et office du juge administratif". RDP, n. ${ }^{\circ}$, 2016.

SOURZAT, LUCIE, Y CLEMMY FRIEDRICH. "La régularisation en droit public". JDA, n. o 6, 2019.

StAUB, MATERne. "L'annulation partielle du permis de construire". Dr. adm., n. o 2, 2014. 
Tesoka, Laurent. "Principe de légalité et principe de sécurité juridique en droit administratif français". AJDA, n. ${ }^{\circ}$ 40, 2006.

THIELE, RenAud. "Annulations partielles et annulations conditionnelles". AJDA, n. ${ }^{\circ} 16,2015$.

JURISPRUDENCIA

\section{Consejo de Estado Colombiano}

Sección Primera, sentencia de 12 de agosto de 1999, exp. 5.500.

Sección Primera, sentencia de 11 de mayo de 2000, exp. 2000-4620.

Sección Primera, sentencia de 18 de julio de 2001, rad. 25000-23-24-000-19922935-01 (6215).

Sección Primera, sentencia de 13 de noviembre de 2008, rad. 76001-23-25-0001997-24274-01.

Sección Primera, sentencia de 8 de julio de 2010, rad. 76001-23-31-000-199920550-01.

Sección Primera, sentencia de 14 de agosto de 2014, rad. 13001-23-31-000-199309425-01.

Sección Primera, sentencia de 28 de agosto de 2014, rad. 76001-23-31-000-200402807-01.

Sección Primera, sentencia de 29 de abril de 2015, rad. 25000-23-24-000-201100329-01 (AP).

Sección Quinta, sentencia de 22 de marzo de 2018, rad. 05001-23-31-000-200800254-01.

Sección Cuarta, sentencia de 20 de noviembre de 2019, rad. 11001-03-15-0002019-04536-00 (AC).

\section{Corte Constitucional de Colombia}

Sentencia C-192, 20 de abril de 2016, exp. D-10974.

Sentencia T-420, 11 de octubre de 2018, exp. T-6. 739.394. 


\section{Jurisprudencia francesa}

CE, Sect., 26 de julio de 1982, Le Roy, n. ${ }^{\circ} 23604$.

CE, 9 de diciembre de 1994, SARL Séri, n. ${ }^{\circ} 116447$.

CE, 2 de febrero de 2004, SCI La Fontaine de Villiers, n. ${ }^{\circ} 238315$.

CE, Ass., 24 de marzo de 2006, Société KPMG, n. 288460.

CE, 17 de junio de 2009, Commune de Grenoble et Communauté d'agglomération Grenoble Alpes Métropole, n. ${ }^{\circ} 301615$.

CE, Ass., 23 de diciembre de 2011, Danthony, n. ${ }^{\circ} 335033$.

CE, 1. ${ }^{\circ}$ de marzo de 2013, Epoux Fritot, n. ${ }^{\circ} 350306$.

CE, 15 de mayo de 2013, sCCV Le Clos de Bonne Brise, n. 341235.

CE, 17 de julio de 2013, SFR, n. ${ }^{\circ} 350380$.

CE, 4 de octubre de 2013, Mme Andrieu, Perrée, n. 358401.

CE, 27 de noviembre de 2013, Association Bois-Guillaume Réflexion, n. ${ }^{o} 358765$.

CE, 30 de diciembre de 2015, SCI Riviera Beauvert, n. ${ }^{\circ} 375276$.

CE, 1. ${ }^{\circ}$ de julio de 2016, Commune d'Emerainville, n. ${ }^{\circ} 363047$.

CE, Sect., 2 de octubre de 2020, n. $^{\circ} 438318$.

Cons. const., 19 de enero de 1995, loi relative à la diversité de l'babitat, n. ${ }^{\circ}$ 94-359 DC.

Cour de cassation, criminelle, Chambre criminelle, 16 de enero de 2018, n. ${ }^{\circ}$ 17-81.157. 